\title{
Carrier dynamic overlapping switching frequency optimal pulse width modulation method for modular multilevel converters
}

\author{
Fayun ZHOU ${ }^{1}$, Qianming XU ${ }^{1}$, An LUO ${ }^{1}$, Zhixing $\mathrm{HE}^{1}$, \\ Yan $\mathrm{LI}^{1,2}$, Ning $\mathrm{XIE}^{3}$, Yichao WANG ${ }^{4}$
}

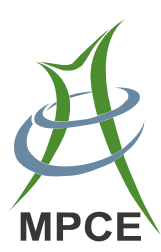

\begin{abstract}
Modular multilevel converters (MMCs) operate in the low modulation index region in many applications. However, when utilized at the low modulation index region, large harmonics appear in the output voltage, which degrade the performance of the MMC. To improve the harmonic characteristic in the low modulation index, the carrier dynamic overlapping switching frequency optimal pulse width modulation (CDOSFOPWM) method is proposed for the MMC here. The whole modulation index region is divided into three regions: high modulation index region, middle modulation index region, and low modulation index region. The carrier amplitude, carrier overlap ratio, and frequency of triangular carriers are chosen dynamically according to the modulation index region of the modulation signals, to achieve the optimal harmonic characteristic in the whole modulation index region and maintain the switching loss. The number of on-state submodules (SMs) can be calculated by CDOSFOPWM, and
\end{abstract}

CrossCheck date: 18 July 2018

Received: 15 August 2017/Accepted: 18 July 2018/Published online: 12 October 2018

(C) The Author(s) 2018

$\triangle$ Qianming XU

hnuxqm@foxmail.com

Fayun ZHOU

hnuzfy@163.com

An LUO

an_luo@126.com

Zhixing HE

hezhixing@163.com

Yan LI

liyanly@csu.edu.cn

Ning XIE

xiening@gddky.csg.cn the selection of SMs is performed by a reducing switching frequency voltage balancing algorithm. Finally, the proposed method is verified by simulation and experimental results.

Keywords Modular multilevel converters, Carrier dynamic overlapping switching frequency optimal pulse width modulation, Harmonic characteristic, Low modulation index

\section{Introduction}

Modular multilevel converters (MMCs) have become a promising multilevel converter topology in medium/highvoltage applications such as high-voltage direct current transmission [1-5], power quality [6-8], medium voltage motor drive [9], integration of renewable energy sources to the electrical grid [10, 11], and battery energy storage systems [12]. In comparison with other multilevel converter topologies, MMCs are characterized by their modular structure, high efficiency, superior harmonic

Yichao WANG

214701903@qq.com

1 College of Electrical and Information Engineering, Hunan University, Changsha 410082, China

2 School of Information Science and Engineering, Central South University, Changsha 410083, China

3 Guangdong Power Grid Co. Ltd. Electric Power Science Research Institute, Guangzhou 510030, China

4 State Grid Hunan Electric Power Corporation Economical \& Technical Research Institute, Changsha 410004, China 
performance, high reliability, and absence of DC-link capacitors [5].

The performance characteristics of MMCs primarily depend on the selection of the particular pulse width modulation method [13, 14]. A variety of modulation methods have been proposed for MMCs [15-34]. The selective harmonic elimination pulse width modulation (SHE-PWM) method generates high-power quality waveforms with low switching frequencies and switching losses. However, the calculation of switching angles increases significantly with the number of voltage levels [14-17]. The nearest level modulation (NLM) method is simple to implement, and is especially suitable for MMCs with a large number of SMs. However, the NLM method introduces round errors due to a round function, which causes poor quality waveforms with low numbers of submodules (SMs) [18-20]. The round errors can be compensated by introducing one SM operating in the pulse width modulation (PWM) mode [21, 22]. The space vector modulation (SVM) method can offer significant flexibility to optimize switching waveforms, and it is suitable for digital implementation. However, the number of switching states and switching sequences primarily increase the number of voltage levels. To reduce the SVM computation, several simplified SVM methods were proposed for MMCs [23-25]. The phase shift carrier pulse width modulation (PSCPWM) method achieves an even power distribution and equalization of the power losses among the SMs [26-28]. The phase disposition pulse width modulation (PDPWM) method has better harmonic characteristics than the PSCPWM method, but the disadvantage of PDPWM method is the uneven power distribution among SMs, which can be improved by a voltage balancing control method based on a sorting algorithm [29-33]. In [34], a modified PWM method with unequal and varying carrier frequencies was proposed, and effectively shifted the primary harmonic content of the output voltages to higher frequencies at the expense of a small increase in low-order harmonics.

Hitherto, few have analyzed the multilevel modulation methods for MMCs in the low modulation index region. However, the MMC will operate in the low modulation index region in many medium/high-voltage applications. The MMC can be used to connect a low-voltage AC source to a high-voltage DC source with a low modulation index, such as DC/AC distribution systems and DC collection of renewable energy [35]. When MMC-based variable-speed motor drives adopt the variable-speed variable-velocity variable-frequency (VVVF) technology, the output voltage of the MMC is proportional to the output frequency. As many medium/high voltage variable speed motor drives typically operate at just a fraction of their rated load [36], the MMC-based motor drive system will often operate in low frequency and low modulation index. The static synchronous compensator (STATCOM) and active power filter (APF) based on MMC may also operate for long durations well below their rated capabilities, such as at night when production has stopped at a commercial or industrial facility [36]. When MMCs are used in a unified power flow controller (UPFC), the output voltage of the series MMC in the MMC-UPFC can be regulated from 0 to the rated value, implying that the modulation index of the output voltage can be regulated from 0 to 1 [37]. Thus, the series MMC in the MMC-UPFC will operate at a low modulation index region in some cases. However, hitherto, few have analyzed the low modulation index operation for the MMC. In [35], a bifurcate MMC for low-modulationratio applications was proposed. Each arm had three branches, and the branch current was lower than the arm current of the conventional MMC. In [37], a harmonic influence analysis of MMC-UPFC based on the NLM was presented, which analyzed the influence of the series MMC in the UPFC on the power grid with different modulation indexes. In [38], a control method of low output frequency operation for the MMC was presented. However, when the MMC operates in the low modulation index region, large harmonics appear in the output voltage, which degrade the MMC performance.

The carrier overlapping pulse width modulation (COPWM) method has superior harmonics in the low modulation index region, and has been implemented in several multilevel converter topologies [39-42]. In [39], the COPWM method was proposed for a diode-clamped multilevel inverter that utilized the control freedom degree (CFD) of vertical offsets among adjacent carriers. The carrier-overlapping switching frequency optimal pulse width modulation (COSFOPWM) method was also presented in [39]. It utilized the CFD of vertical offsets between adjacent carriers, and the CFD of injecting zero sequence signals to the reference voltages; further, the modulation index can be increased to 1.15. In [40], the COPWM method with voltage balance for flying capacitor multilevel inverters was proposed, which showed better harmonics performance than the phase-shifted carrier pulse width modulation (PSCPWM) method in the low modulation index region. In [41], the harmonic characteristics analysis of the COPWM method for a five-level diodeclamped multilevel inverter was presented, which indicated that the carrier overlapping ratio for optimal harmonic characteristics was different in different modulation index regions. In [42], the COPWM and COSFOPWM methods for a cascaded three-level voltage source inverter were proposed. However, the output voltage of COPWM contains some low-order harmonics in the high modulation index region, which causes a relatively high total harmonics distortion (THD) of the output current. Meanwhile, 
each carrier corresponds to a specific voltage level; when the modulation signal is over one carrier, the corresponding level is generated. Therefore, the switches will be used only when the corresponding level is reached, causing an uneven power distribution among the switches [43].

To the authors' best knowledge, the COPWM method for MMCs has not been studied in previous literatures. To achieve the optimal harmonic characteristic in the whole modulation index region, the carrier dynamic overlapping switching frequency optimal pulse width modulation (CDOSFOPWM) method for MMC is proposed herein. The whole modulation index region is divided into three regions: high modulation index region, middle modulation index region, and low modulation index region. To achieve the optimal harmonic characteristic in different modulation index regions and maintain the switching loss for the SMs, the carrier amplitude, carrier overlap ratio, and frequency are chosen dynamically according to the modulation index region of the modulation signal. The number of on-state SMs is calculated by CDOSFOPWM, and the capacitor voltage balancing is achieved by the capacitor balancing control method.

This paper is organized as follows. Section 2 proposes the CDOSFOPWM method. Section 3 presents the simulation results for the PSCPWM and CDOSFOPWM methods. The proposed method is verified by the experimental results on a three-phase MMC prototype in Section 4. Finally, the conclusions are summarized in Section 5 .

\section{CDOSFOPWM method for MMC}

The circuit topology of a three-phase MMC is shown in Fig. 1. Each phase comprises two arms: the upper arm and lower arm. Each arm consists of $N$ series-connected identical SMs and a series inductor $L$. The resistance $R$ represents the power loss for the SMs and the resistances of the inductors.

The reference voltage of the upper and lower arms can be expressed as:

$u_{u x, \mathrm{ref}}=\frac{U_{d c}}{2}\left[1+M \cos \left(\omega_{o} t+\pi+\varphi_{x}\right)\right]$

$u_{l x, \text { ref }}=\frac{U_{d c}}{2}\left[1+M \cos \left(\omega_{o} t+\varphi_{x}\right)\right]$

where $u_{u x, \text { ref }}$ and $u_{l x, \text { ref }}$ are the reference voltages of the upper and lower arms for phase $x(x \in\{a, b, c\})$, respectively; $U_{d c}$ is the DC-link voltage; $M$ denotes the modulation index; $\varphi_{x}\left(\varphi_{a}=0, \varphi_{b}=-2 \pi / 3, \varphi_{c}=-2 \pi / 3\right)$ is the phase angle of phase $x$.

The zero-sequence voltages of the upper arm and lower arm can be derived as:

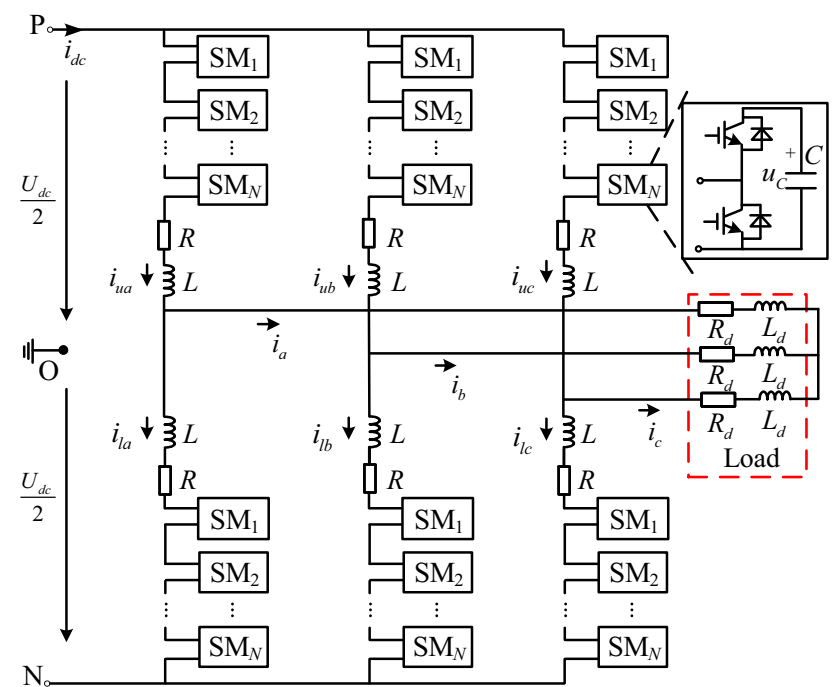

Fig. 1 Circuit topology of MMC

$u_{u z}=\frac{\max \left(u_{u a, \text { ref }}, u_{u b, \text { ref }}, u_{u c, \text { ref }}\right)+\min \left(u_{u a, \text { ref }}, u_{u b, \text { ref }}, u_{u c, \text { ref }}\right)}{2}$

$u_{l z}=\frac{\max \left(u_{l a, \text { ref }}, u_{l b, \text { ref }}, u_{l c, \text { ref }}\right)+\min \left(u_{l a, \text { ref }}, u_{l b, \text { ref }}, u_{l c, \text { ref }}\right)}{2}$

The modulation signals of the upper and lower arms for phase $x$ can be calculated as:

$u_{u x, \bmod }=u_{u x, \mathrm{ref}}-u_{u z}$

$u_{l x, \text { mod }}=u_{l x, \text { ref }}-u_{l z}$

where $u_{u x, \bmod }$ and $u_{l x, \text { mod }}$ are the modulation signals of the upper and lower arms for phase $x$, respectively. The modulation index can be increased to 1.15 by injecting a zero-sequence voltage into the reference voltage [17], which improves the DC-voltage utilization of the MMC.

The principle of CDOSFOPWM for MMCs is shown in Fig. 2. The number of SMs per arm is $N=8$. Each arm consists of $N$ carriers with the same amplitude $A$, frequency $f_{c}$, and phase angle $\varphi$. The vertical overlapping ratio between adjacent carriers is $p(0 \leq p<1)$, which can be obtained as:

$p=\frac{N\left(A-U_{C}\right)}{(N-1) A}$

where $U_{C}$ is the rated capacitor voltage of the SMs. Assuming that the ripples of the capacitor voltage of the SMs are negligible, $U_{C}=U_{d c} / N$.

The carrier overlapping quantity can be obtained as:

$q=p A=\frac{N\left(A-U_{C}\right)}{N-1}$ 
where $q$ is the carrier overlapping quantity.

The carrier displacement angle between the upper arm carriers and lower arm carriers is $\pi$. The carriers for the upper and lower arms can be calculated as:

$u_{u n, t r i}=\left\{\begin{array}{lc}-\frac{A}{\pi}\left(\omega_{c} t-2 k \pi+\pi\right)+A(1-p)(n-1) & 2 k \pi \leq \omega_{c} t<2 k \pi+\pi \\ \frac{A}{\pi}\left(\omega_{c} t-2 k \pi+\pi\right)+A(1-p)(n-1) & 2 k \pi+\pi \leq \omega_{c} t<2 k \pi+2 \pi\end{array}\right.$

$u_{l n, t r i}=\left\{\begin{array}{l}\frac{A}{\pi}\left(\omega_{c} t-2 k \pi+2 \pi\right)+A(1-p)(n-1) \quad 2 k \pi \leq \omega_{c} t<2 k \pi+\pi \\ -\frac{A}{\pi}\left(\omega_{c} t-2 k \pi\right)+A(1-p)(n-1) \quad 2 k \pi+\pi \leq \omega_{c} t<2 k \pi+2 \pi\end{array}\right.$

where $u_{u n, t r i}$ and $u_{l n, t r i}$ are the triangular carriers for the upper and lower arms, respectively; $\omega_{c}$ is the angular frequency of the triangular carriers; $k(k \in\{1,2, \ldots\})$ is the carrier period; $n(n \in\{1,2, \ldots, N\})$ refers to the $n$th carrier.

The whole modulation index region of the modulation signals can be divided into three modulation regions: high modulation index region, middle modulation index region, and low modulation index region. The carrier overlapping ratio, carrier amplitude and frequency are chosen dynamically according to the modulation region of the reference voltage, to achieve the optimal harmonic characteristics in the three regions.

$A_{l}, A_{m}, A_{h}$ are defined as the carrier amplitudes in the low modulation, middle modulation, and high modulation index regions, respectively. $p_{l}, p_{m}, p_{h}$ are defined as the carrier overlapping ratio in the low modulation, middle modulation, and high modulation index regions, respectively.

When the carrier overlapping ratio $p=p_{l}$, the peak value of the $(N-2)$ th carrier can be expressed as:

$L_{N-2}=A_{l}+A_{l}\left(1-p_{l}\right)(N-3)$

where $L_{N-2}$ is the peak value of $(N-2)$ th carrier.

When the carrier overlapping ratio $p=p_{m}$, the peak value of $(N-1)$ th carrier can be obtained as:

$D_{N-1}=A_{m}+A_{m}\left(1-p_{m}\right)(N-2)$
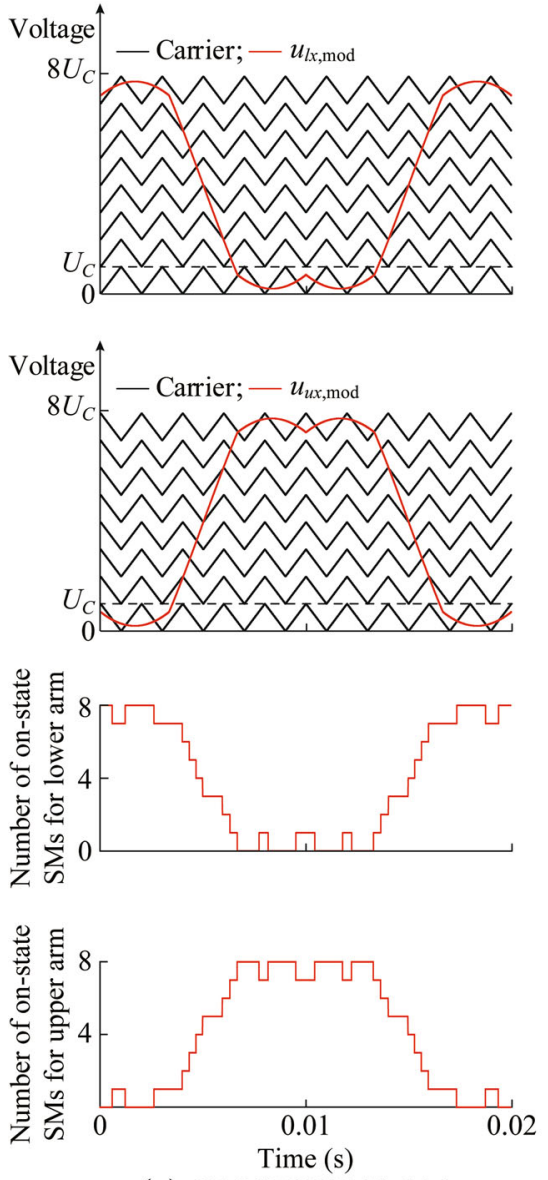

(a) CDOSFOPWM in high modulation index region
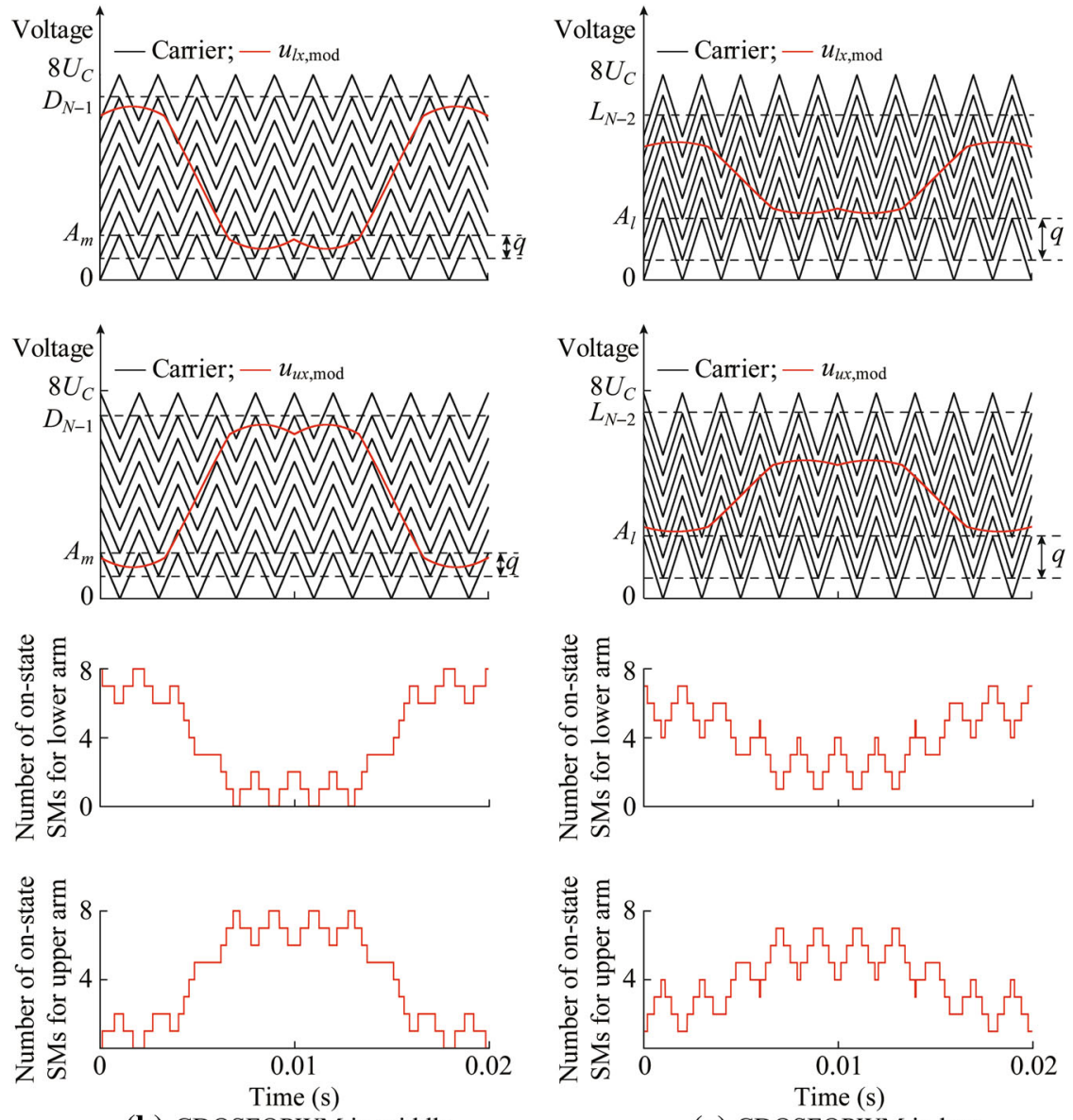

(b) CDOSFOPWM in middle modulation index region

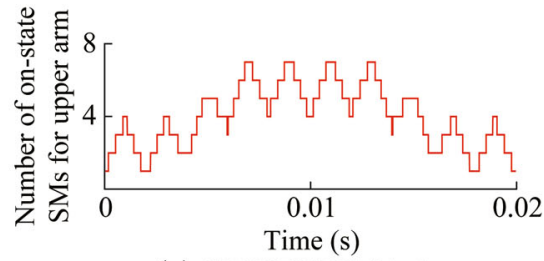

(c) CDOSFOPWM in low modulation index region

Fig. 2 Principle of CDOSFOPWM method for MMC 
The range of the high modulation region, middle modulation region, and low modulation region can be defined as follows:

If the peak value of all the modulation signals $u_{y x \text {,mod }}$ satisfies the condition as shown in (13), then the MMC operates in the low modulation region.

$0<u_{y x, \bmod }<L_{N-2}$

where subscript $y \in\{u, l\}$ refers to the upper and lower arms.

If the peak value of any modulation signals $u_{y x \text {,mod }}$ satisfies the condition as shown in (14), then the MMC operates in the middle modulation region.

$L_{N-2} \leq u_{y x, \bmod } \leq D_{N-1}$

If the peak value of all the modulation signals $u_{y x \text {,mod }}$ satisfies the condition as shown in (15), then the MMC operates in the high modulation region.

$D_{N-1}<u_{y x, \bmod } \leq \frac{1.15 U_{d c}}{2}$

When the carrier overlapping ratio $p=p_{l}=0.66$, optimal harmonic characteristic can be achieved for the MMC in the low modulation region. However, the carrier amplitude may be an irrational number (e.g., if $N=10$, the carrier amplitude $A_{l}=10 U_{C}$ /4.06). To produce a carrier overlapping ratio equaling to or rounding to 0.66 , the carrier amplitude, frequency, and carrier overlapping ratio in the low modulation index region can be calculated as:

$$
\left\{\begin{array}{l}
A=A_{l}=U_{C}\left[\frac{N-1}{10^{t}} \times \operatorname{round}\left(\frac{33 \times 10^{t}}{17 N+33}\right)+1\right] \\
f_{c}=f_{l} \\
p=p_{l}=\frac{(N-1)\left(A_{l}-U_{C}\right)}{A_{l}(N-2)}
\end{array}\right.
$$

where the function round $(x)$ will obtain the nearest integer of $x ; t(t \in\{2,3, \ldots\})$ represents that the carrier amplitude is correct to $t$ decimal places, and $t$ is selected as 2 herein; $f_{c}$ is the carrier frequency; $f_{l}$ is the carrier frequency in the low modulation index region.

When the carrier overlapping ratio $p=p_{m}=0.5$, optimal harmonic characteristic can be achieved for the MMC in the middle modulation region. To produce a carrier overlapping ratio equaling to or rounding to 0.5 , the carrier amplitude, carrier frequency, and carrier overlapping ratio in the middle modulation index region can be obtained as:

$$
\left\{\begin{array}{l}
A=A_{m}=U_{C}\left[\frac{N-1}{10^{t}} \times \operatorname{round}\left(\frac{10^{t}}{N+1}\right)+1\right] \\
f_{c}=f_{m}=1.5 f_{l} \\
p=p_{m}=\frac{N\left(A_{m}-U_{C}\right)}{A_{m}(N-1)}
\end{array}\right.
$$

where $f_{m}$ is the carrier frequency in the middle modulation index region.

As shown in Fig. 2, the average intersecting number within each carrier period, between the modulation signal and $N$ triangular carriers in each arm at the high, middle, and low modulation index regions are 2,4 , and 6 , respectively. This means that the number of on-state SMs are changed 2, 4, and 6 times, respectively. When the carrier frequency in the high modulation index region is three times the carrier frequency in the low modulation index region, and the carrier frequency in middle modulation index region is 1.5 times the carrier frequency in the low modulation index region, the average switching frequency and power loss in the three modulation index regions are the same.

When the carrier overlapping ratio $p=p_{h}=0$, optimal harmonic characteristic can be achieved for the MMC in the high modulation index region. The carrier amplitude, carrier frequency, and carrier overlapping ratio in the high modulation region can be expressed as:

$\left\{\begin{array}{l}A=A_{h}=U_{C} \\ f_{c}=f_{h}=3 f_{l} \\ p=p_{h}=0\end{array}\right.$

where $f_{h}$ is the carrier frequency in the high modulation index region. As shown, when carrier the overlapping ratio $p=p_{h}=0$, the CDOSFOPWM method is equivalent to the PDPWM method in the high modulation index region.

Figure 3 shows the flowchart of the CDOSFOPWM method. The number of on-state SMs for each arm can be calculated by CDOSFOPWM, and the selection of SMs is performed by reduced switching frequency (RSF) of the voltage balancing algorithm [44]. Herein, $u_{y x \text {, ref }}$ is the reference voltage of the upper arm and lower arm of phase; $u_{\text {tri,yn }}$ refers to the triangular carrier of the upper and lower arms $(n \in\{1,2, \ldots, N\}) ; n_{y x}$ is the number of on-state SMs of the upper and lower arms of phase $x$; $i_{y x}$ represents the arm current of phase $x ; u_{y x}[i](i \in\{1,2, \ldots, N\})$ is the SMs capacitor voltage of the upper and lower arms for phase $x$.

The procedure of each arm for the CDOSFOPWM method is as follows:

1) The modulation signals $u_{y x \text {,mod }}$ of the upper and lower arms can be calculated by (3)-(6). The flowchart of the dynamic carrier generator is shown in Fig. 4. The carrier amplitude, frequency, and carrier overlapping ratio can be obtained by (16)-(18) according to the modulation index region of the modulation signals, and the triangular carriers $u_{t r i, y n}$ are generated by (9) and (10).

2) The number of on-state SMs can be obtained according to the carrier dynamic overlapping modulation by 
comparing the modulation signals with $N$ triangular carriers in each arm.

3) The selection of SMs can be performed by the RSF voltage balancing control algorithm according to the direction of the arm current and capacitor voltage of the SMs in each arm; this can reduce the switching frequency of the SMs and achieve capacitor voltage balancing.

\section{Simulation results}

To verify the proposed method, a three-phase MMC inverter with eight SMs per arm is developed using the PSIM software. The parameters of the simulation are shown in Table 1.

The CDOSFOPWM method and PSCPWM method are compared in three modulation index regions with the same average switching frequency and power loss. It is noteworthy that the modulation index can be increased to 1.15 for the PSCPWM method by injecting zero-sequencing components into the reference voltages of the upper arm and lower arm. The carrier frequency for the PSCPWM method is $f_{p s c}=300 \mathrm{~Hz}$, whereas the carrier frequency for CDOSFOPWM is $f_{c}=f_{h}=2400 \mathrm{~Hz}$ in the high modulation index region, $f_{c}=f_{m}=1200 \mathrm{~Hz}$ in the middle modulation index region, and $f_{c}=f_{l}=800 \mathrm{~Hz}$ in the low modulation index region. Thus, the average switching frequency of each SM for the CDOSFOPWM method and PSCPWM method is approximately $300 \mathrm{~Hz}$ in the whole modulation index region.

According to (13)-(15), the modulation region in each arm can be calculated as follows: low modulation index region, $0<M<0.7$; middle modulation index region, $0.7 \leq M \leq 0.9$; high modulation index region, $0.9<M$ $\leq 1.15$. The carrier amplitudes for CDOSFOPWM are $A=A_{l}=2.4 U_{C}$ in the low modulation region, $A=A_{m}=1.77 U_{C}$ in the middle modulation region, and $A=A_{h}=U_{C}$ in the high modulation region.

The modulation index is selected as $M=1.1$ in the high modulation index region, $M=0.8$ in the middle modulation index region, and $M=0.4$ in the low modulation index region.

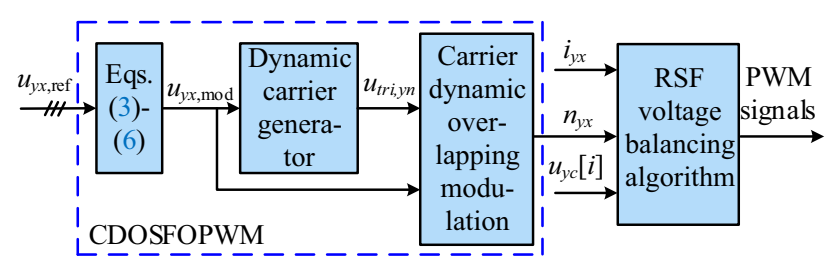

Fig. 3 Flowchart of CDOSFOPWM method

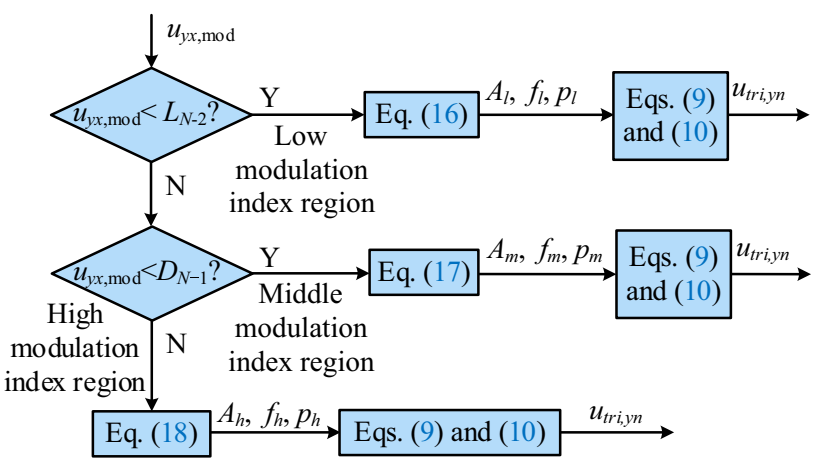

Fig. 4 Flowchart of dynamic carrier generator

Table 1 Parameters of simulation

\begin{tabular}{ll}
\hline Parameter & Value \\
\hline Number of SMs per arm, $N$ & 8 \\
DC-link voltage, $U_{d c}$ & $8000 \mathrm{~V}$ \\
Rated SM capacitor voltage, $U_{C}$ & $1000 \mathrm{~V}$ \\
Arm inductance, $L$ & $2 \mathrm{mH}$ \\
Arm equivalent resistance, $R$ & $0.1 \Omega$ \\
SM Capacitance, $C$ & $10 \mathrm{mF}$ \\
Load inductance, $L_{d}$ & $2 \mathrm{mH}$ \\
Load resistance, $R_{d}$ & $30 \Omega$ \\
High modulation index, $M_{h}$ & 1.1 \\
Middle modulation index, $M_{m}$ & 0.8 \\
Low modulation index, $M_{l}$ & 0.4 \\
Carrier frequency for CDOSFOPWM in low modulation & $800 \mathrm{~Hz}$ \\
$\quad$ index region, $f_{l}$ & \\
Carrier frequency for CDOSFOPWM in middle & $1200 \mathrm{~Hz}$ \\
$\quad$ modulation index region, $f_{d}$ & \\
Carrier frequency for CDOSFOPWM in high modulation & $2400 \mathrm{~Hz}$ \\
$\quad$ index region, $f_{h}$ & \\
Carrier frequency for PSCPWM, $f_{p s c}$ & $300 \mathrm{~Hz}$ \\
\hline
\end{tabular}

The THD of the line-to-line voltage and phase current with different carrier amplitudes and modulation indexes are shown in Fig. 5.

It is noteworthy that the THD of the line-to-line voltage cannot exactly represent the harmonic performance as the line-to-line voltage contains some low-frequency harmonics in the high modulation index region when the carrier amplitude $A=2.4 U_{C}$ and $A=1.77 U_{C}$, which are difficult to be filtered and increase the THD of the phase current. To accurately evaluate the harmonic characteristics of the MMC, the THD of the phase current is presented in Fig. 5b.

As shown, when the carrier amplitude $A=A_{l}=2.4 U_{C}$, the THD of the phase current is the lowest in the low modulation region. When the carrier amplitude $A=A_{m}=1.77 U_{C}$, the overall optimal harmonic 
performance is achieved in the middle modulation region. When the carrier amplitude $A=A_{h}=U_{C}$, the overall optimal harmonic performance can be achieved in the high modulation region. The CDOSFOPWM method selects the carrier amplitude and carrier overlapping ratio dynamically according to the modulation index region of the modulation signals. Thus, the optimal harmonic characteristic can be achieved in the whole modulation region.

The simulation results of PSCPWM and CDOSFOPWM for the MMC with modulation index $M=1.1$ are shown in Fig. 6 and Fig. 7, respectively. Herein, $u_{a}, u_{a b}$, and $i_{a}$ are the phase voltage, line-to-line voltage, and phase current, respectively.

The simulation results of the PSCPWM method and CDOSFOPWM method in the middle modulation index region with modulation index $M=0.8$ are depicted in Fig. 8 and Fig. 9, respectively.

The simulation results of the PSCPWM method and CDOSFOPWM method for the MMC in the low modulation index region with modulation index $M=0.4$ are presented in Fig. 10 and Fig. 11, respectively.

We found that the equivalent switching frequency of the phase voltage for the PSCPWM method is $f_{\text {equ,psc }}=N f_{p s c}=8 \times 300 \mathrm{~Hz}=2400 \mathrm{~Hz}$ in the whole modulation index region. The harmonic components of the phase voltage for PSCPWM are the sideband harmonic components of the carrier groups, especially the sideband harmonics of the first carrier group. We found that the equivalent switching frequency of the phase voltage for the CDOSFOPWM method is $f_{\text {equ,cdo }}=f_{h}=2400 \mathrm{~Hz}$ in the

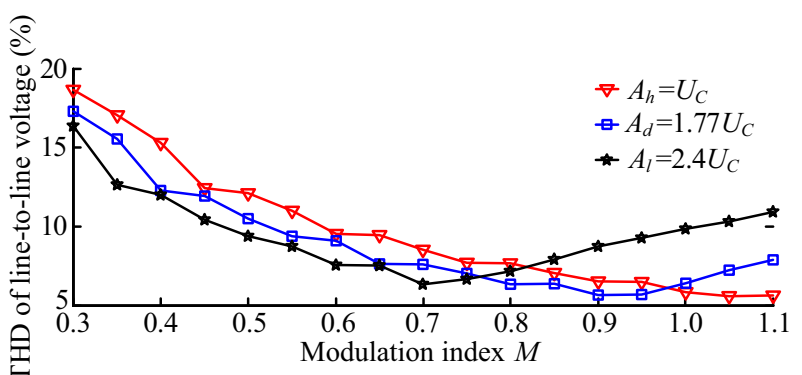

(a) THD of line-to-line voltage with different modulation indexes

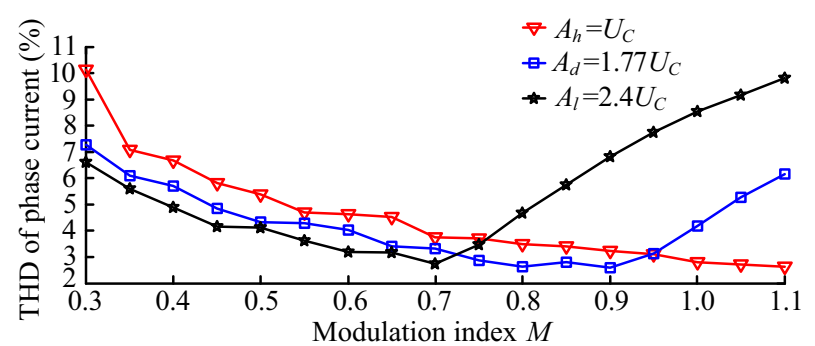

(b) THD of phase current with different modulation indexes

Fig. 5 THD of line-to-line voltage and phase current with different carrier amplitudes and modulation indexes high modulation index region, $f_{\text {equ,cdo }}=f_{m}=1200 \mathrm{~Hz}$ in the middle modulation index region, and $f_{\text {equ,cdo }}=$ $f_{l}=800 \mathrm{~Hz}$ in the low modulation index region.

As shown, the primary harmonic components in the phase voltage of the CDOSFOPWM method are the carrier harmonic components, especially the first carrier component, which can be cancelled in the line-to-line voltage, as shown in Fig. 7b, Fig. 9b, and Fig. 11b. Thus, superior harmonic characteristics can be achieved for the CDOSFOPWM method. Further, the zero-sequence harmonic voltages (triplen frequency) in the phase voltage are eliminated in the line-to-line voltage.

As shown in Fig. 6b, Fig. 8b, and Fig. 10b, the primary harmonic components of the line-to-line voltage for the PSCPWM method are the sideband harmonics of $N f_{p s c}=2400 \mathrm{~Hz}$, whereas the primary harmonic components in the line-to-line voltage of the CDOSFOPWM method are the sideband harmonic components of $2 f_{h}=4800 \mathrm{~Hz}$ in the whole modulation index region, as shown in Fig. 7b, Fig. 9b, and Fig. 11b. This implies that the size of the filters can be reduced with the same THD requirements. In addition, the magnitude of the harmonic components in the line-to-line voltage and the phase current for CDOSFOPWM are lower than those for PSCPWM.

Table 2 shows the comparison of simulation results between the CDOSFOPWM method and PSCPWM method for the MMC.

We found that the total switching number per arm in one power grid period for PSCPWM is 48 times in the whole modulation index region, whereas the total switching number in one power grid period for the CDOSFOPWM method is 46 times in the high modulation region, 48 times in the middle modulation region, and 47 times in the low modulation region. The total switching number in one power grid period for the PSCPWM and CDOSFOPWM methods are the same in the whole region of modulation index.
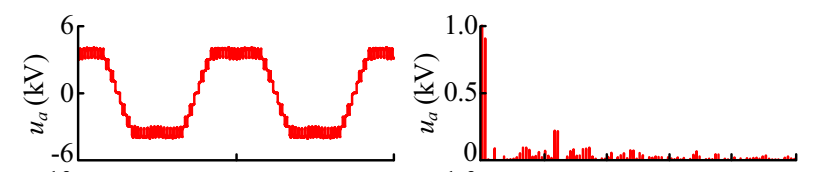

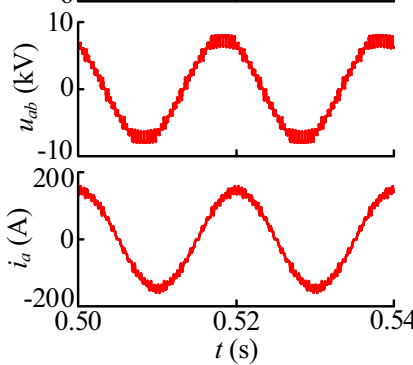

(a) Simulation waveforms

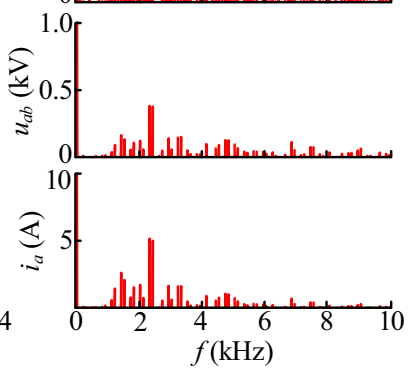

(b) Harmonic spectrums
Fig. 6 Simulation results of PSCPWM method in high modulation index region with $M=1.1$ 


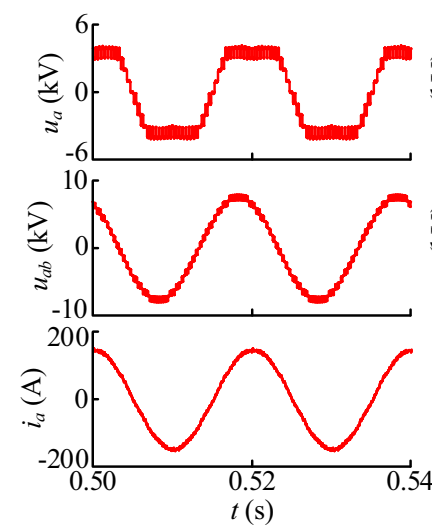

(a) Simulation waveforms

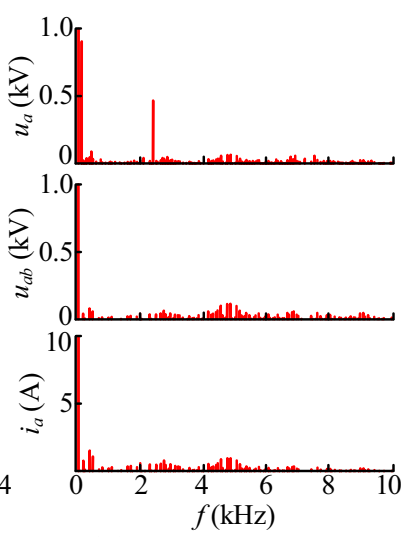

(b) Harmonic spectrums

Fig. 7 Simulation results of CDOSFOPWM in middle modulation index region with $M=1.1$

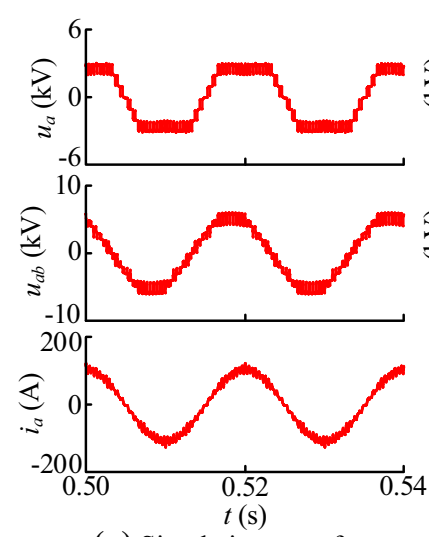

(a) Simulation waveforms

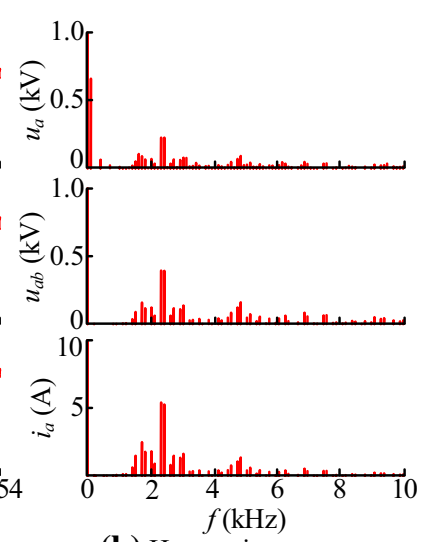

(b) Harmonic spectrums

Fig. 8 Simulation results of PSCPWM method in middle modulation index region with $M=0.8$

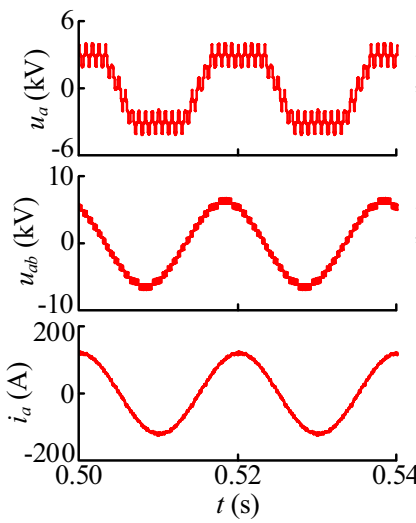

(a) Simulation waveforms

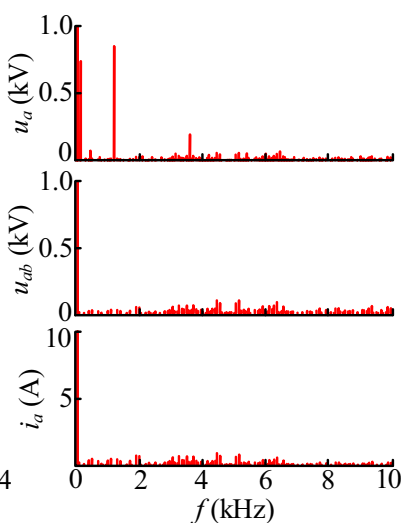

(b) Harmonic spectrums

Fig. 9 Simulation results of CDOSFOPWM method in middle modulation index region with $M=0.8$

In the high modulation index region, when modulation index $M=1.1$, the THDs of the line-to-line voltage and phase current for the PSCPWM method are $10.11 \%$ and

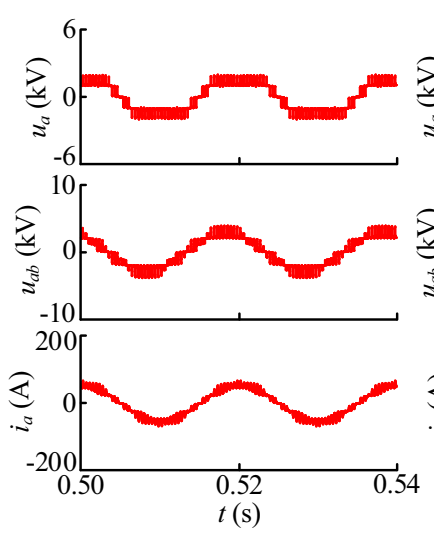

(a) Simulation waveforms

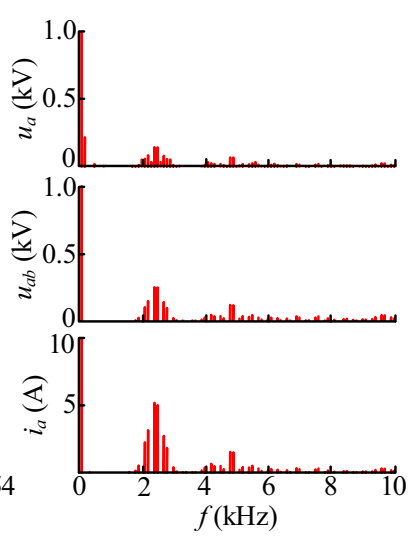

(b) Harmonic spectrums
Fig. 10 Simulation results of PSCPWM method in low modulation index region with $M=0.4$

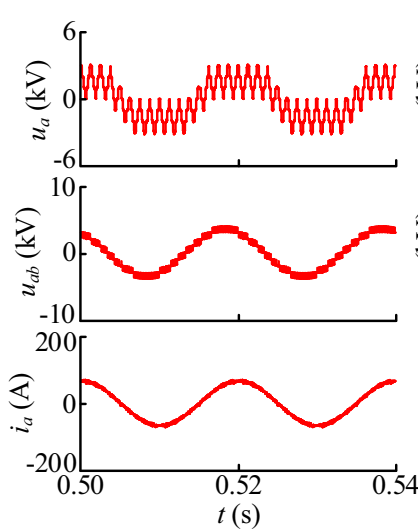

(a) Simulation waveforms

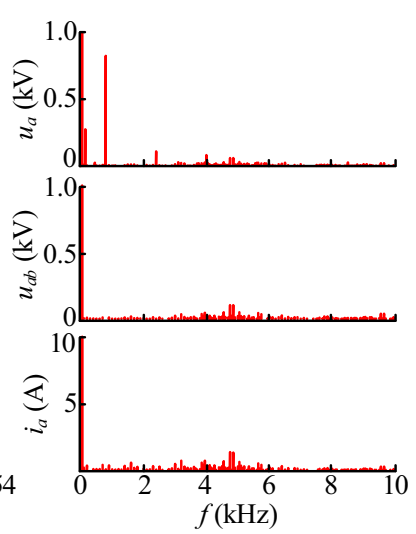

(b) Harmonic spectrums
Fig. 11 Simulation results of CDOSFOPWM method in low modulation index region with $M=0.4$

$6.40 \%$, respectively. Meanwhile, the THD of the line-toline voltage and phase current for CDOSFOPWM are $5.64 \%$ and $2.63 \%$, respectively.

In the middle modulation index region, when modulation index $M=0.8$, the THD of the line-to-line voltage and phase current for the PSCPWM method are $14.01 \%$ and $8.84 \%$, respectively; whereas the THDs of the line-to-line voltage and phase current for CDOSFOPWM are 6.36\% and $2.63 \%$, respectively.

In the low modulation index region, when modulation index $M=0.4$, the THDs of the line-to-line voltage and phase current for PSCPWM are $27.99 \%$ and $17.48 \%$, respectively; whereas the THDs of the line-to-line voltage and phase current for CDOSFOPWM are $12.00 \%$ and $4.89 \%$, respectively.

The THD of the line-to-line voltage for the CDOSFOPWM method and PSCPWM method with different modulation indexes are shown in Fig. 12.

We found that when the total switching number is the same, the CDOSFOPWM method has better harmonic 
Table 2 Comparison of simulation results between CDOSFOPWM method and PSCPWM method for MMC

\begin{tabular}{lccl}
\hline Modulation method & THD of line-to-line voltage $(\%)$ & THD of phase current $(\%)$ & Switching number per arm in one period \\
\hline CDOSFOPWM $(M=1.1)$ & 5.64 & 2.63 & 46 \\
PSCPWM $(M=1.1)$ & 10.11 & 6.40 & 48 \\
CDOSFOPWM $(M=0.8)$ & 6.36 & 2.63 & 48 \\
PSCPWM $(M=0.8)$ & 14.01 & 8.84 & 48 \\
CDOSFOPWM $(M=0.4)$ & 12.00 & 4.89 & 47 \\
PSCPWM $(M=0.4)$ & 27.99 & 17.48 & 48 \\
\hline
\end{tabular}

characteristics than the PSCPWM method in the whole modulation index region, especially in the middle modulation index region and the low modulation index region.

\section{Experimental verification}

To further verify the proposed method, a three-phase MMC prototype is built. The experiment parameters are shown in Table 3. Each arm contains four SMs. A resistive load is employed in the experiment.

The modulation index regions can be obtained according to (13)-(15): low modulation index region, $0<M<0.4$; middle modulation index region, $0.4 \leq M \leq 0.7$; high modulation index region, $0.7<M \leq 1.15$. The carrier amplitudes for CDOSFOPWM are $A=A_{l}=1.99 U_{C}$ in the low modulation index region, $A=A_{m}=1.6 U_{C}$ in the middle modulation index region, and $A=A_{h}=U_{C}$ in the high modulation index region. The modulation indexes are chosen as $M=1.1$ in the high modulation index region, $M=0.55$ in the middle modulation index region, and $M=0.35$ in the low modulation index region. The average switching frequency of each SM for the CDOSFOPWM method and PSCPWM method is $900 \mathrm{~Hz}$.

The experimental results of the PSCPWM method and CDOSFOPWM method for the MMC in the high modulation index region with $M=1.1$ are shown in Fig. 13 and Fig. 14, respectively.

The experimental results of the PSCPWM method and CDOSFOPWM method for the MMC in the middle modulation index region with $M=0.55$ are presented in Fig. 15 and Fig. 16, respectively.

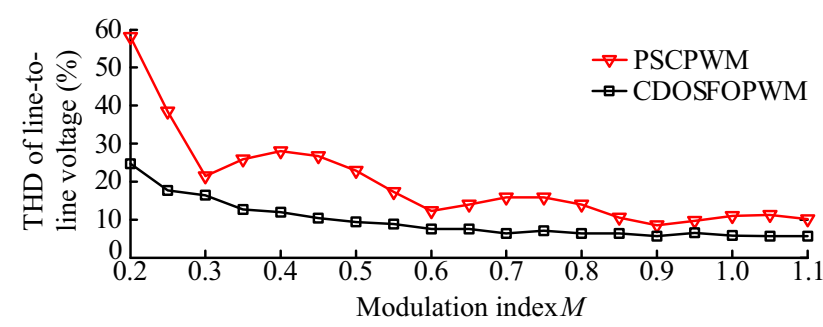

Fig. 12 THD of line-to-line voltage for CDOSFOPWM method and PSCPWM method with different modulation indexes
The experimental results of the PSCPWM method and CDOSFOPWM method for the MMC in the low modulation index region with $M=0.35$ are shown in Fig. 17 and Fig. 18, respectively.

As shown in Fig. 13b, Fig. 15b, and Fig. 17b, the equivalent switching frequency of the phase voltage for the PSCPWM method in the whole modulation index region is $N f_{p s c}=4 \times 900 \mathrm{~Hz}=3600 \mathrm{~Hz}$. The primary harmonic components of the phase voltage and line-to-line voltage are the sideband harmonic of $3600 \mathrm{~Hz}$.

The equivalent switching frequency of the phase voltage for the CDOSFOPWM method is $3600 \mathrm{~Hz}\left(f_{\text {equ,cdo }}=f_{h}\right)$ in the high modulation index region, $1800 \mathrm{~Hz}\left(f_{\text {equ, cdo }}=f_{m}\right)$ in the middle modulation index region, and $1200 \mathrm{~Hz}$ $\left(f_{\text {equ,cdo }}=f_{l}\right)$ in the low modulation index region, as shown in Fig. 14b, Fig. 16b, and Fig. 18b, respectively. It is noteworthy that most harmonic components in the phase voltage are the first carrier harmonic component, which is eliminated in the line-to-line voltage. Therefore, superior

Table 3 Parameters of MMC prototype

\begin{tabular}{ll}
\hline Parameter & Value \\
\hline DC-link voltage, $U_{d c}$ & $400 \mathrm{~V}$ \\
Rated SM capacitor voltage, $U_{C}$ & $100 \mathrm{~V}$ \\
Number of SMs per arm, $N$ & 4 \\
Arm inductance, $L$ & $1 \mathrm{mH}$ \\
SM capacitance, $C$ & $10 \mathrm{mF}$ \\
Load inductance, $L_{d}$ & $1 \mathrm{mH}$ \\
Load resistance, $R_{d}$ & $10 \Omega$ \\
High modulation index, $M_{h}$ & 1.1 \\
Middle modulation index, $M_{m}$ & 0.55 \\
Low modulation index, $M_{l}$ & 0.35 \\
Carrier frequency for CDOSFOPWM in low modulation & $1200 \mathrm{~Hz}$ \\
$\quad$ index region, $f_{l}$ & $1800 \mathrm{~Hz}$ \\
Carrier frequency for CDOSFOPWM in middle & \\
$\quad$ modulation index region, $f_{d}$ & $3600 \mathrm{~Hz}$ \\
Carrier frequency for CDOSFOPWM in high modulation & \\
$\quad$ index region, $f_{h}$ & $900 \mathrm{~Hz}$ \\
\hline Carrier frequency for PSCPWM, $f_{p s c}$ &
\end{tabular}




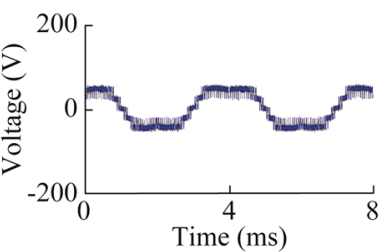

(a) Phase voltage of PSCPWM

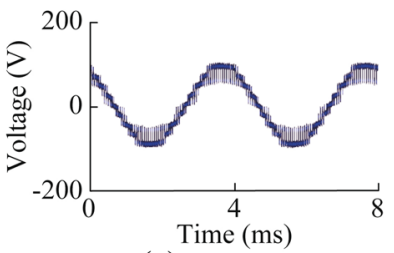

(c) Line-to-line voltage of PSCPWM

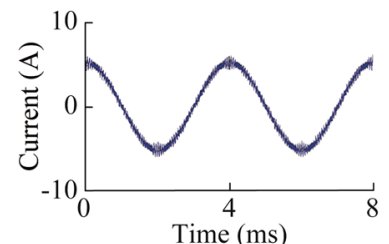

(e) Phase current of PSCPWM

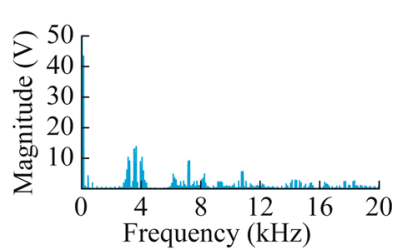

(b) Harmonic spectrum of phase voltage

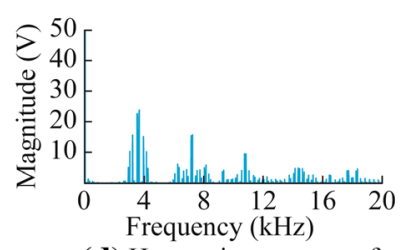

(d) Harmonic spectrum of line-to-line voltage

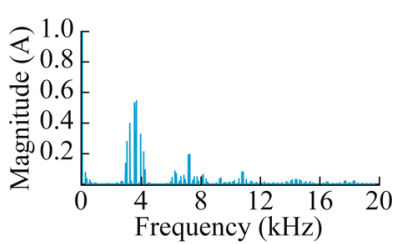

(f) Harmonic spectrum of phase current

Fig. 13 Experiment results of PSCPWM method in high modulation region with $M=1.1$

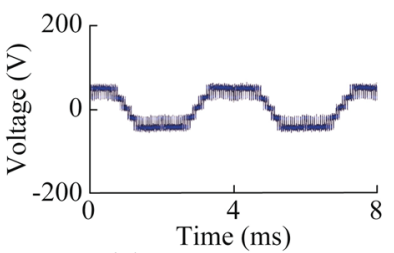

(a) Phase voltage of CDOSFOPWM

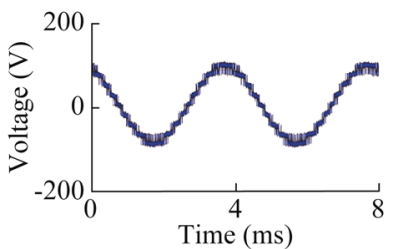

(c) Line-to-line voltage of CDOSFOPWM

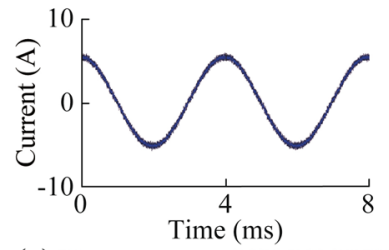

(e) Phase current of CDOSFOPWM

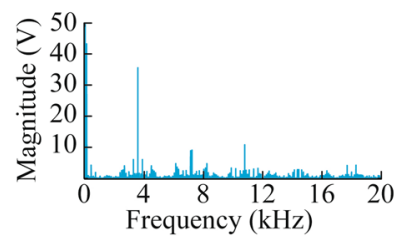

(b) Harmonic spectrum of phase voltage

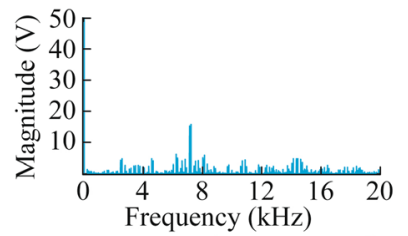

(d) Harmonic spectrum of line-to-line voltage

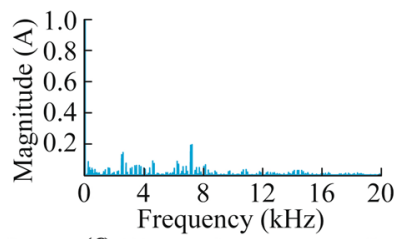

(f) Harmonic spectrum of phase current

Fig. 14 Experimental results of CDOSFOPWM method for MMC in high modulation index region with $M=1.1$

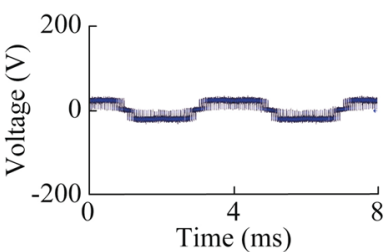

(a) Phase voltage of PSCPWM

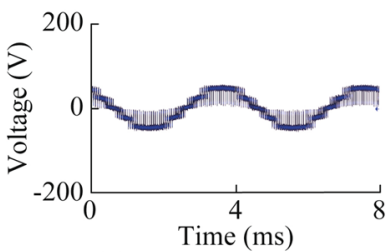

(c) Line-to-line voltage of PSCPWM

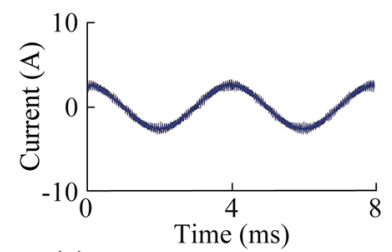

(e) Phase current of PSCPWM

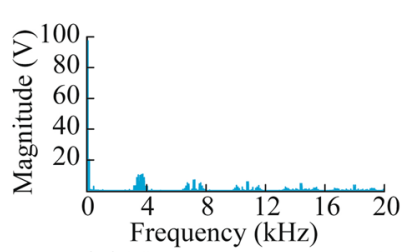

(b) Harmonic spectrum of phase voltage

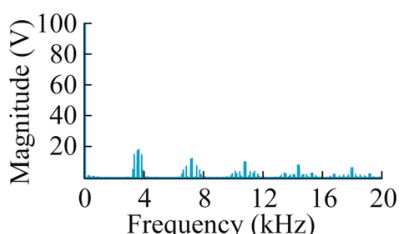

(d) Harmonic spectrum of line-to-line voltage

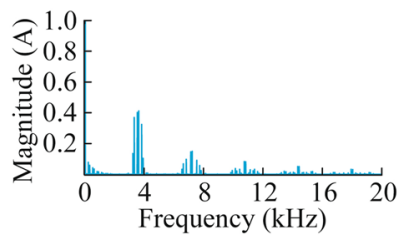

(f) Harmonic spectrum of phase current
Fig. 15 Experiment results of PSCPWM method for MMC in middle modulation index region with $M=0.55$

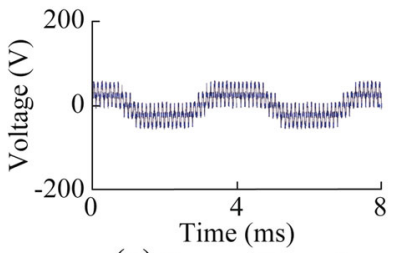

(a) Phase voltage of CDOSFOPWM

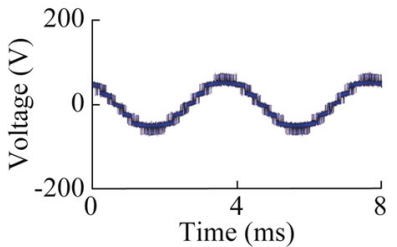

(c) Line-to-line voltage of CDOSFOPWM

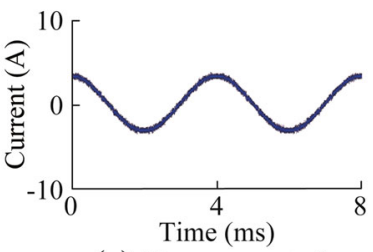

(e) Phase current of CDOSFOPWM

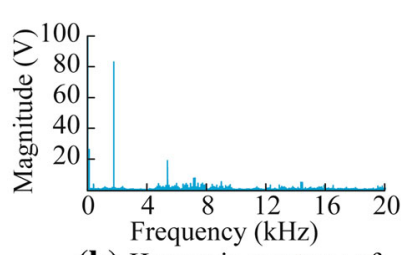

(b) Harmonic spectrum of phase voltage

(d) Harmonic spectrum of

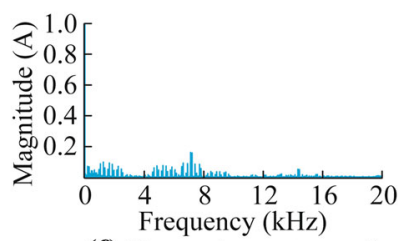

(f) Harmonic spectrum of phase current

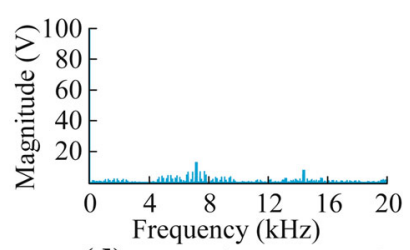
line-to-line voltage

Fig. 16 Experimental results of CDOSFOPWM method for MMC in middle modulation index region with $M=0.55$ 


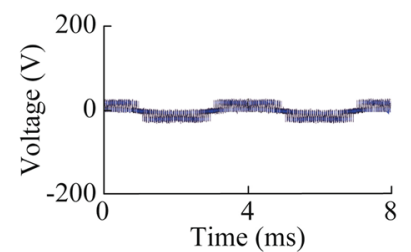

(a) Phase voltage of PSCPWM

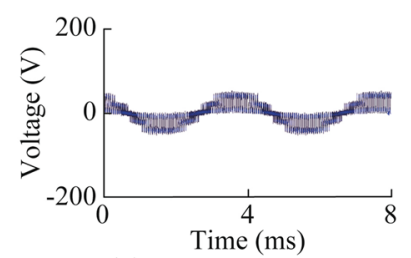

(c) Line-to-line voltage of PSCPWM

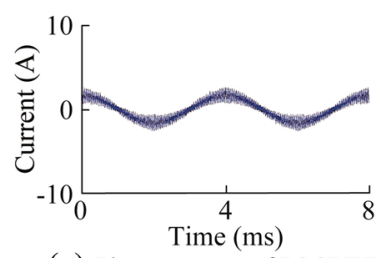

(e) Phase current of PSCPWM

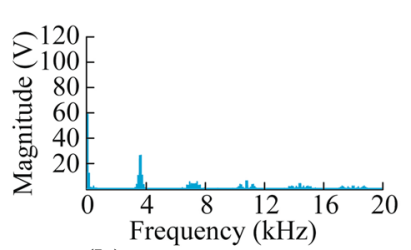

(b) Harmonic spectrum of phase voltage

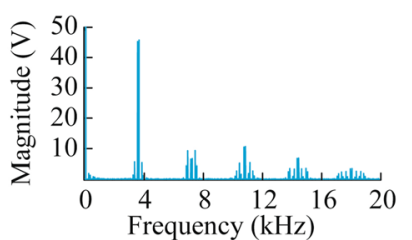

(d) Harmonic spectrum of line-to-line voltage

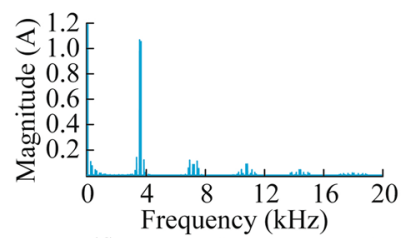

(f) Harmonic spectrum of phase current

Fig. 17 Experiment results of PSCPWM method for MMC in low modulation index region with $M=0.35$

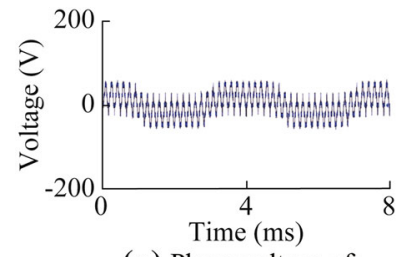

(a) Phase voltage of CDOSFOPWM

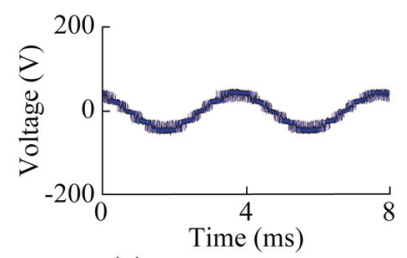

(c) Line-to-line voltage of CDOSFOPWM

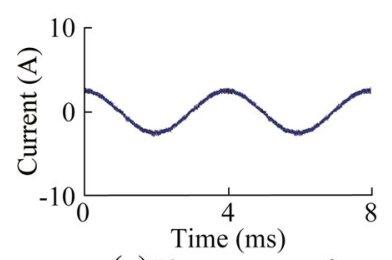

(e) Phase current of CDOSFOPWM

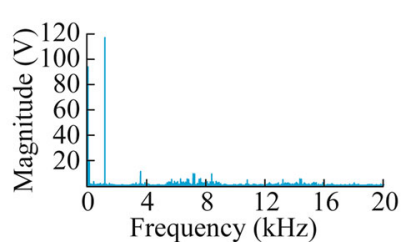

(b) Harmonic spectrum of phase voltage

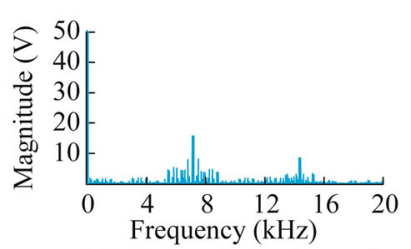

(d) Harmonic spectrum of line-to-line voltage

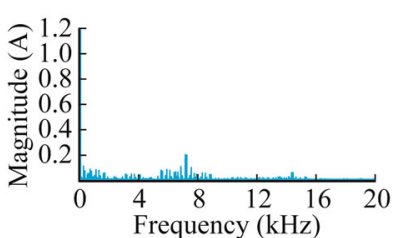

(f) Harmonic spectrum of phase current

Fig. 18 Experiment results of CDOSFOPWM method for MMC in low modulation index region with $M=0.35$

Table 4 Comparison of experimental results between CDOSFOPWM method and PSCPWM method

\begin{tabular}{lll}
\hline Modulation method & $\begin{array}{l}\text { THD of line-to- } \\
\text { line voltage }(\%)\end{array}$ & $\begin{array}{l}\text { THD of phase } \\
\text { current }(\%)\end{array}$ \\
\hline CDOSFOPWM $(M=1.1)$ & 11.89 & 2.61 \\
PSCPWM $(M=1.1)$ & 17.55 & 5.47 \\
CDOSFOPWM $(M=0.55)$ & 19.15 & 4.16 \\
PSCPWM $(M=0.55)$ & 32.06 & 8.97 \\
CDOSFOPWM $(M=0.35)$ & 26.41 & 5.54 \\
PSCPWM $(M=0.35)$ & 73.58 & 26.03
\end{tabular}

harmonic characteristics can be achieved for the CDOSFOPWM method. As shown in Fig. 14d, Fig. 16d, and Fig. 18d, the primary harmonic components of the line-toline voltage for CDOSFOPWM are the sideband harmonic components of $7200 \mathrm{~Hz}$ in the whole modulation index region. This implies that the lower THD of the line-to-line voltage and phase current can be achieved.

Table 4 shows the comparison of experimental results between the CDOSFOPWM and PSCPWM methods.

In the high modulation index region, when modulation index $M=1.1$, the THDs of the line-to-line voltage and phase current for the PSCPWM method are $16.05 \%$ and $5.15 \%$, respectively; whereas the THDs of the line-to-line voltage and phase current for the CDOSFOPWM method are $10.77 \%$ and $2.50 \%$, respectively.

In the middle modulation index region, when modulation index $M=0.55$, the THDs of the line-to-line voltage and phase current for the PSCPWM method are $27.52 \%$ and $7.85 \%$, respectively; whereas the THDs of the line-toline voltage and phase current for the CDOSFOPWM method are $16.89 \%$ and $3.79 \%$, respectively.

In the low modulation index region, when modulation index $M=0.35$, the THDs of the line-to-line voltage and phase current for the PSCPWM method are $63.05 \%$ and $22.81 \%$, respectively; whereas the THDs of the line-to-line voltage and phase current for the CDOSFOPWM method are $22.62 \%$ and $4.88 \%$, respectively.

The experimental results further demonstrate that the CDOSFOPWM method has better harmonic characteristics than the PSCPWM method in the whole modulation region.

\section{Conclusion}

This paper proposed the CDOSFOPWM method for MMCs. The whole modulation index region was divided into three regions: high modulation index region, middle modulation index region, and low modulation index region. The carrier amplitude, carrier overlap ratio, and frequency of triangular carriers were chosen dynamically according to the modulation index region of the modulation signal, to 
achieve the optimal harmonic characteristic in the whole modulation index region and maintain the switching loss. The number of on-state SMs was calculated by CDOSFOPWM, and the selection of SMs was performed by reducing the switching frequency voltage balancing algorithm. The simulation and experiment results demonstrated that the CDOSFOPWM method exhibited superior harmonic characteristics than the PSCPWM method in the whole modulation region.

Acknowledgment This work was supported by National Natural Science Foundation of China (No. 51477045).

Open Access This article is distributed under the terms of the Creative Commons Attribution 4.0 International License (http:// creativecommons.org/licenses/by/4.0/), which permits unrestricted use, distribution, and reproduction in any medium, provided you give appropriate credit to the original author(s) and the source, provide a link to the Creative Commons license, and indicate if changes were made.

\section{References}

[1] Lesnicar A, Marquardt R (2003) An innovative modular multilevel converter topology suitable for a wide power range. In: Proceedings of the 2003 IEEE Bologna power tech conference, Bologna, Italy, 23-26 June 2003, 6 pp

[2] Glinka M, Marquardt R (2005) A new AC/AC multilevel converter family. IEEE Trans Ind Electron 52(3):662-669

[3] Akagi H (2011) Classification, terminology, and application of the modular multilevel cascade converter (MMCC). IEEE Trans Power Electron 26(11):3119-3130

[4] Perez MA, Bernet S, Rodriguez J et al (2015) Circuit topologies, modeling, control schemes, and applications of modular multilevel converters. IEEE Trans Power Electron 30(1):4-17

[5] Debnath S, Qin JC, Bahrani B et al (2015) Operation, control, and applications of the modular multilevel converter: a review. IEEE Trans Power Electron 30(1):37-53

[6] Luo A, Xu QM, Ma FJ et al (2016) Overview of power quality analysis and control technology for the smart grid. J Mod Power Syst Clean Energy 4(1):1-9

[7] Mohammadi HP, Bina MT (2011) A transformerless mediumvoltage STATCOM topology based on extended modular multilevel converters. IEEE Trans Power Electron 26(5):1943-1957

[8] Zhuo GY, Jiang DZ, Lian XR (2012) Modular multilevel converter for unified power flow controller application. In: Proceedings of the third international conference on digital manufacturing and automation (ICDMA), Guilin, China, 31 July-2 August 2012, pp 545-549

[9] Hagiwara M, Nishimura K, Akagi H (2010) A medium-voltage motor drive with a modular multilevel PWM inverter. IEEE Trans Power Electron 25(7):1786-1799

[10] Debnath S, Saeedifard M (2013) A new hybrid modular multilevel converter for grid connection of large wind turbines. IEEE Trans Sust Energy 4(4):1051-1064

[11] Mei J, Xiao BL, Shen K et al (2013) Modular multilevel inverter with new modulation method and its application to photovoltaic grid-connected generator. IEEE Trans Power Electron 28(11):5063-5073

[12] Trintis I, Munk-Nielsen S, Teodorescu R et al (2011) A new modular multilevel converter with integrated energy storage. In:
Proceedings of 37th annual conference on IEEE industrial electronics society, Melbourne, Australia, 7-10 November 2011, pp 1075-1080

[13] Leon JI, Kouro S, Franquelo LG et al (2016) The essential role and the continuous evolution of modulation techniques for voltage-source inverters in the past, present, and future power electronics. IEEE Trans Ind Electron 63(5):2688-2701

[14] Dahidah MSA, Konstantinou G, Agelidis VG (2015) A review of multilevel selective harmonic elimination PWM: formulations, solving algorithms, implementation and applications. IEEE Trans Power Electron 30(8):4091-4106

[15] Ilves K, Antonopoulos A, Norrga S et al (2012) A new modulation method for the modular multilevel converter allowing fundamental switching frequency. IEEE Trans Power Electron 27(8):3482-3494

[16] Konstantinou G, Ciobotaru M, Agelidis V (2013) Selective harmonic elimination pulse-width modulation of modular multilevel converters. IET Power Electron 6(1):96-107

[17] Basante AP, Ceballos S, Konstantinou G et al $(2018)(2 N+1)$ selective harmonic elimination-PWM for modular multilevel converters: a generalized formulation and a circulating current control method. IEEE Trans Power Electron 33(1):802-818

[18] Tu QR, Xu Z (2011) Impact of sampling frequency on harmonic distortion for modular multilevel converter. IEEE Trans Power Deliv 26(1):298-306

[19] Meshram PM, Borghate VB (2015) A simplified nearest level control (NLC) voltage balancing method for modular multilevel converter (MMC). IEEE Trans on Power Electron 30(1):450-462

[20] Hu PF, Jiang DZ (2015) A level-increased nearest level modulation method for modular multilevel converters. IEEE Trans Power Electron 30(4):1836-1842

[21] Rohner S, Bernet S, Hiller M et al (2010) Modulation, losses, and semiconductor requirements of modular multilevel converters. IEEE Trans Ind Electron 57(8):2633-2642

[22] Li ZX, Wang P, Zhu HB et al (2012) An improved pulse width modulation method for chopper-cell-based modular multilevel converters. IEEE Trans Power Electron 27(8):3472-3481

[23] Deng Y, Harley RG (2015) Space-vector versus nearest-level pulse width modulation for multilevel converters. IEEE Trans on Power Electron 30(6):2962-2974

[24] Deng Y, Wang YB, Teo KH et al (2016) A simplified space vector modulation scheme for multilevel converters. IEEE Trans Power Electron 31(3):1873-1886

[25] Dekka A, Wu B, Zargari NR et al (2016) A space-vector PWMbased voltage-balancing approach with reduced current sensors for modular multilevel converter. IEEE Trans on Ind Electron 63(5):2734-2745

[26] Hagiwara M, Akagi H (2009) Control and experiment of pulse width-modulated modular multilevel converters. IEEE Trans Power Electron 24(7):1737-1746

[27] Ilves K, Harnefors L, Norrga S et al (2015) Analysis and operation of modular multilevel converters with phase-shifted carrier PWM. IEEE Trans Power Electron 30(1):268-283

[28] Li BB, Yang RF, Xu DD et al (2015) Analysis of the phaseshifted carrier modulation for modular multilevel converters. IEEE Trans Power Electron 30(1):297-310

[29] Darus R, Pou J, Konstantinou G et al (2015) A modified voltage balancing algorithm for the modular multilevel converter: evaluation for staircase and phase-disposition PWM. IEEE Trans Power Electron 30(8):4119-4127

[30] Mcgrath BP, Teixeira CA, Holmes DG (2015) Optimised phase disposition (PD) modulation of a modular multilevel converter using a state machine decoder. In: Proceedings of 2015 IEEE energy conversion congress and exposition (ECCE), Montreal, Canada, 20-24 September 2015, pp 6368-6375 
[31] Hassanpoor A, Norrga S, Nee HP et al (2012) Evaluation of different carrier-based PWM methods for modular multilevel converters for HVDC application. In: Proceedings of 38th annual conference on IEEE industrial electronics society (IECON), Montreal, Canada, 25-28 October 2012, pp 388-393

[32] Darus R, Konstantinou G, Pou J et al (2014) Comparison of phase-shifted and level-shifted PWM in the modular multilevel converter. In: Proceedings of 2014 international power electronics conference (ECCE-ASIA), Hiroshima, Japan, 18-21 May 2014, pp 3764-3770

[33] Baú DF, da Silva GS, Pinheiro H et al (2016) PD modulation strategy for modular multilevel converters. In: Proceedings of the 12th IEEE international conference on industry applications (INDUSCON), Curitiba, Brazil, 20-23 November 2016, pp 1-6

[34] Konstantinou G, Darus R, Pou J et al (2014) Varying and unequal carrier frequency PWM techniques for modular multilevel converters. In: Proceedings of 2014 international power electronics conference (ECCE-ASIA), Hiroshima, Japan, 18-21 May 2014, pp 3758-3763

[35] Chang YR, Cai X, Zhang JW et al (2016) Bifurcate modular multilevel converter for low-modulation-ratio applications. IET Power Electron 9(2):145-154

[36] Tolbert LM, Peng FZ, Habetler TG (2000) Multilevel PWM methods at low modulation indices. IEEE Trans Power Electron 15(4):719-725

[37] Yuan YB, Li P, Kong XP et al (2016) Harmonic influence analysis of unified power flow controller based on modular multilevel converter. J Mod Power Syst Clean Energy 4(1):10-18

[38] Korn A, Winkelnkemper M, Steimer P (2010) Low output frequency operation of the modular multilevel converter. In: Proceeding of IEEE energy conversion congress and exposition, Atlanta, USA, 12-16 September 2010, pp 3993-3997

[39] Wang HY, Zhao RX, Deng Y et al (2003) Novel carrier-based PWM methods for multilevel inverter. In: Proceedings of 29th annual conference on IEEE industrial electronics society, Roanoke, USA, 2-6 November 2003, pp 2777-2782

[40] Wang HY, Deng Y, He XN (2004) Novel carrier-based PWM method with voltage balance for flying capacitor multilevel inverters. In: Proceedings of the 2004 IEEE power electronics specialists conference, Orlando, USA, 17-21 June 2004, pp 4423-4427

[41] Deng Y, Wang HY, Zhang C et al (2005) Multilevel PWM methods based on control degrees of freedom combination and its theoretical analysis. In: Proceedings of the 2005 IEEE industry applications conference fortieth IAS annual meeting, Hong Kong, China, 2-6 October 2005, pp 1692-1699

[42] Hridya I, Srinivas S (2015) Carrier overlapped PWM switching schemes for a cascaded three level voltage source inverter. In: Proceedings of the 2015 IEEE international conference on industrial technology (ICIT), Seville, Spain, 17-19 March 2015, pp 3028-3033

[43] Angulo M, Lezana P, Kouro S et al (2007) Level-shifted PWM for cascaded multilevel inverters with even power distribution. In: Proceedings of the 2007 IEEE power electronics specialists conference (PESC'07), Orlando, USA, 17-21 June 2007, pp 2373-2378

[44] Tu QR, Xu Z, Xu L (2011) Reduced switching-frequency modulation and circulating current suppression for modular multilevel converters. IEEE Trans Power Del 26(3):2009-2017 toward the Ph.D. degree in Hunan University since 2012. His research interests include modulation of multilevel converters, power quality control technique.

Qianming XU received the B.S. degree in Electrical Engineering and Automation and $\mathrm{Ph} . \mathrm{D}$. degree in Electrical Engineering from Hunan University, Changsha, in 2012 and 2017, respectively. Since 2017, he has been an Assistant Professor with the College of Electrical and Information Engineering, Hunan University. His research interests include modular multilevel converter, power quality control, DC grid control.

An LUO received the Ph.D. degree in fluid power transmission and control from Zhejiang University, Hangzhou, China, in 1993. Between 1996 and 2002, he was a professor with Central South University. Since 2003, he has been a professor in the College of Electrical and Information Engineering, Hunan University, where he also serves as the Chief of National Electric Power Conversion and Control Engineering Technology Research Center. He has published over 100 journal and conference articles. He is engaged in research on power conversion systems, harmonic suppression and reactive power compensation, and electric power saving.

Zhixing HE received the B.S. degree from the College of Information Science and Engineering, Central South University, Changsha, China, in 2011. He received the Ph.D. degree in the College of Electrical and Information Engineering, Hunan University, Changsha, China, in 2016. He is currently a postdoctoral fellow at Hunan University. His current research interests include model predictive control, modular multilevel converter, high-frequency link power conversion system.

Yan LI received her B.S., M.S., and Ph.D. degrees in automatic, disaster prevention, and mitigation engineering and pattern recognition and intelligent system from Central South University, Changsha, China in 1999, 2003, and 2007, respectively. She also performs research works in the electrical engineering post-doctoral research station of Hunan University. She has been working as a teacher in the School of Science Information and Engineering of Central South University, Changsha, China. Her current research interests include power quality, power electronic technology and system, and control for inverters in micro grids.

Ning XIE received the B.S. degree from Shandong Jiaotong University, Jinan, China, in 2010. He received the Ph.D. degree in the College of Electrical and Information Engineering, Hunan University, Changsha, China, in 2015. He is currently an engineer in Guangdong Power Grid Co. Ltd. Electric Power Science Research Institute. His current research interests include power quality and distributed generation.

Yichao WANG received the B.S. degree from the College of Information science and Engineering, Changsha University of Science and Technology, Changsha, China, in 2010. He received the Ph.D. degree in the College of Electrical and Information Engineering, Hunan University, Changsha, China, in 2015. He is currently an engineer in State Grid Hunan Electric Power Corporation Economical \& Technical Research Institute. His current research interests include power quality and microgrid.

Fayun ZHOU received the B.S. degree from Hunan University of Humanities, Science and Technology in 2010. He has been working 